\title{
Hybrid half-bridge package for high voltage application
}

\author{
Bassem Mouawad, Jianfeng Li, Alberto Castellazzi, C. Mark Johnson \\ Power Electronics, Machines and Control Group (PEMC) \\ University of Nottingham, University Park Campus \\ NG7 2RD, Nottingham, United Kingdom \\ bassem.mouawad@nottingham.ac.uk
}

\begin{abstract}
D power module structures allow for better cooling and lower parasitic inductances compared with the classical planar technology. In this paper, we present a hybrid half-bridge in a 3D packaging configuration, dedicated for high voltage application. A dynamic electrical test of the package is presented.
\end{abstract}

Keywords- Half-Bridge, 3-D Packaging, Power Electronics, High Voltage, Si IGBT, SiC Diodes

\section{INTRODUCTION}

The known requirements for insulated gate bipolar transistor (IGBT) modules in electricity network applications include high isolation voltage $(>10 \mathrm{kV})$, excellent cooling performance and high reliability. Present state-of-art manufacturing for plastic packaged IGBT modules involves the solder attachment of the dies to a substrate followed by ultrasonic bonding of IGBT emitter and diode anode connections, there being up to 600 individual bonds in a large module. Creation of such a large number of individual bonds is expensive, time consuming and a source of yield loss. Moreover, the thermal management arrangements in conventional modules remove heat from just one die surface, restricting the maximum heat flux that can be sustained for a given maximum junction temperature.

Over the past years, several replacements of wire-bonds, such as ribbon-bond, dimple array, embedded chip technology, silicon interposer, solder bump, metal bump and press-pack bus-bar-like interconnects have been proposed and investigated worldwide [1]. These replacements have been demonstrated to obtain dramatic improvement in the thermal and electromagnetic performance, and/or allow advanced integration schemes, e.g. stacked devices, for the optimization of basic power switch topologies, e.g. half bridge switch and bi-directional switch [2]. However, these interconnect techniques can be used to overcome only one or two aspects of the above problems for the IGBT modules. Also, there are concerns about the reliability and manufacturability for the implementation of these techniques. Other researchers have worked on so-called "sandwich structures" or "3-D structures", which use two similar substrates with the dies in-between. These solutions are designed to offer double-side cooling of the devices [3]-[5].
In the present work, we describe an innovative packaging design that can simultaneously overcome the mechanical, electrical and thermal limitations of conventional modules.

\section{CONCEPT OF THE STRUCTURE}

A planar module for a half-bridge switch has been designed for demonstrating the present work to address the abovementioned problems in the conventional IGBT modules. The designed module has a compact volume of $104 \mathrm{~mm} \times 103 \mathrm{~mm}$ $\times 23 \mathrm{~mm}$, including an integrated turbulent cooler for double side cooling. It's been developed for fully Si power module. Knowing the benefit of the hybrid package on the reduction of the switching losses [6], the presented design in this work will be a hybrid package that accommodates $2 \mathrm{Si}$ IGBTs and $4 \mathrm{SiC}$ junction barrier Schottky (JBS) diodes which can be selected from devices with ability of blocking voltages up to $10 \mathrm{kV}$. Flexible printed circuit boards (PCBs) have been proposed as an alternative solution for Aluminum (Al) wirebonding technology, and been used on the "SKiN" power module for the internal connections that allows to have very low inductance comparing to that of $\mathrm{Al}$ wirebonds [7]. However, copper $(\mathrm{Cu})$ bulk busbars were used for the power terminals.

In the presented design, a flexible PCB is employed not only as an intermediate interconnect of smaller features on power devices, but also as a replacement of conventional bus bars. This can makes use of the established PCB technology to achieve the spatial resolution to contact power device features, and at the same time reduce the lengths of conducting loops in the power modules for achieving extremely low parasitic inductance. Mechanical structures were introduced in order to achieve sufficient insulating distance. Moreover, sintering of silver (Ag) nanoparticles is used as joining technology for improving the reliability of the power module under high power density conditions.

\section{MANUFACTURING PROCESS}

\section{A. Materials and preparation of the Dies}

The materials used to build the half-bridge package are as follows:

- 2x Direct Bonded Copper (DBC) substrates

- 2 x $3.3 \mathrm{kV}$ Si IGBT

- 4 x $3.3 \mathrm{kV} \mathrm{SiC} \mathrm{JBS} \mathrm{diodes}$ 


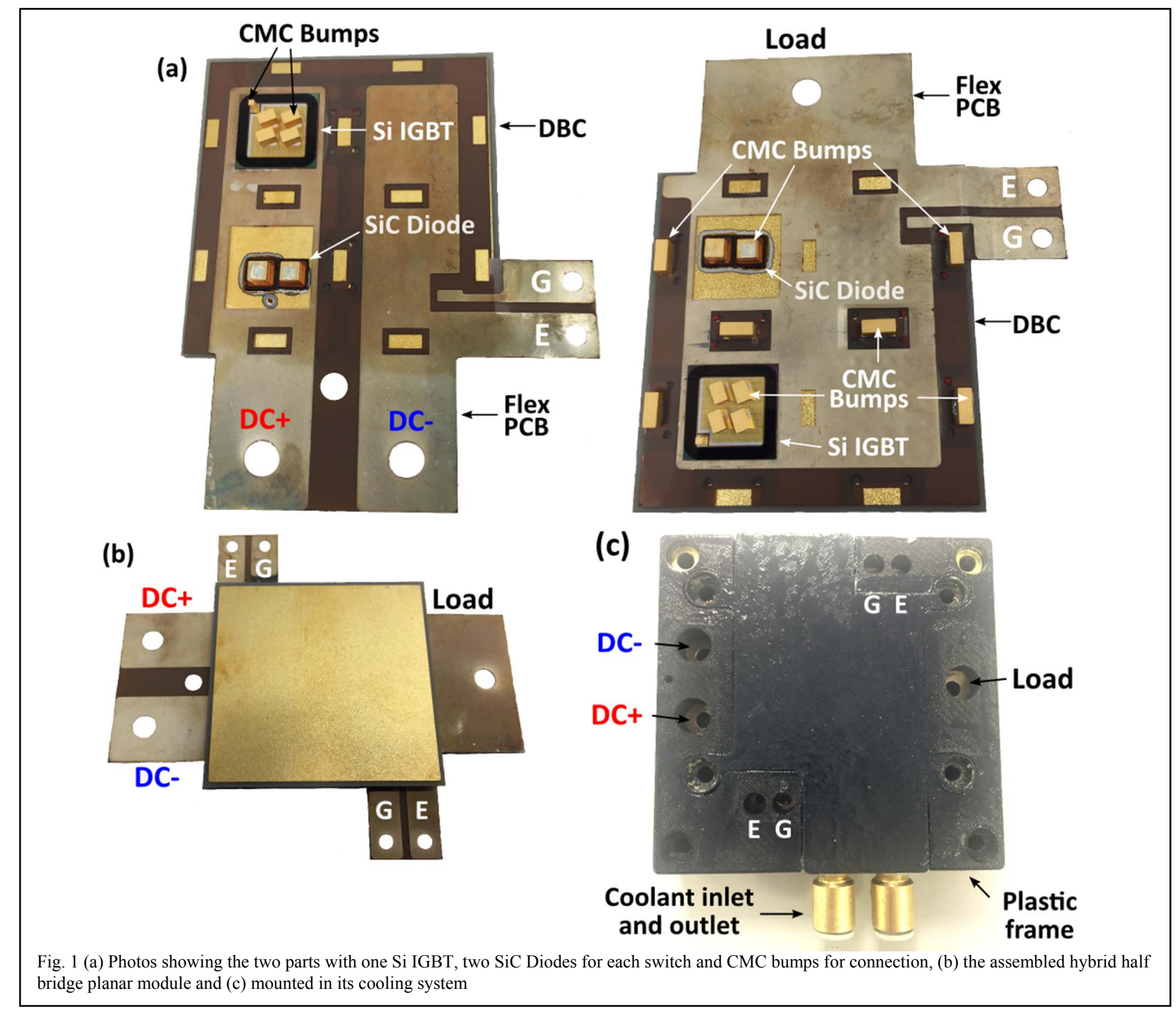

- Flexible PCBs to replace Al wire bonds and $\mathrm{Cu}$ busbars in conventional power modules

- Copper/Molybdenum/Copper (CMC) composite brick bumps for achieving sufficient insulating distance and a better mechanical structure [1].

- Plastic frame integrated turbulent cooler that allows a double-side cooling.

From a device point of view, as these are commercially available with standard aluminum top terminology, a deposition of a new metal layer on the top of the existing $\mathrm{Al}$ is required to be suitable with the bonding technology. Therefore, thin titanium (Ti) and gold $(\mathrm{Au})$ layers are then deposited on the $\mathrm{Al}$ pad of the dies to make it compatible with the $\mathrm{Ag}$ sintering technology.

For the DBC substrate, and for facilitating the Ag sintering technology, $\sim 5 / 0.1 \mu \mathrm{m}$ thick $\mathrm{NiP} / \mathrm{Au}$ finish has been added on all the $\mathrm{Cu}$ layers of the DBC substrates. For the flex PCB, the $\mathrm{Cu}$ layers were finished with $\mathrm{Ag}$ layer.

\section{B. Assembly process}

Fig. 1 shows all the parts and the assembling process of the presented hybrid half-bridge package. It should be noted that both the upper and lower switches are bonded separately on each DBC substrate. Each switch contains $1 \mathrm{Si}$ IGBT and $2 \mathrm{SiC}$ diodes and the flex PCB. Plasma etching was used to remove any residual organic contamination, prior to the assembly process. The latter was performed as follows:

- First, the two Si IGBTs and the corresponding flex PCBs are bonded on the DBCs using Ag sintering technology

- The SiC JBS Diodes are then soldered on the DBCs

- A die bonder is then employed for both accurate positioning of the CMC bumps on the top-side of each device and the sintering step (cf. Fig. 1 a) 


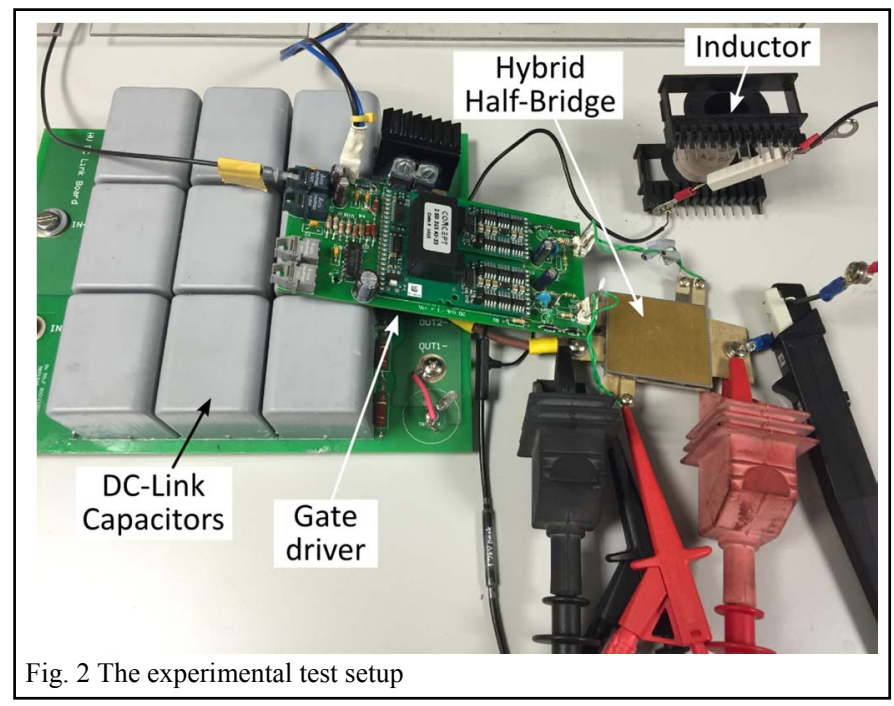

- The two parts are then bonded together using solder technology; Fig. $1 \mathrm{~b}$

- For insulation, the assembly is then filled with Silicone Gel under vacuum and cured at $125^{\circ} \mathrm{C}$.

The assembled hybrid half-bridge planar module (shown in Fig. $1 \mathrm{~b}$ ) is then mounted in its cooling system that allows a double-side direct cooling of the planar module (cf. Fig. $1 \mathrm{c}$ ).

\section{ELECTRICAL CHARACTERIZATION}

Double-pulse test is a widely used approach to characterize the parasitic electric parameters of power module packaging and to test the switching performance of the latter. It is performed by operating the phase leg (or half bridge) module in a standard switching process including switch-on, conduction, switch-off and block with inductive load, which can control the current going through the switches and voltage applied. This test was carried out at room temperature on the designed hybrid half-bridge.

The experimental parameters are list below in Table I. The lower side IGBT of the half bridge is the device under test

Table I Experimental parameters

\begin{tabular}{|l|c|}
\hline \multicolumn{2}{|c|}{ Double Pulse test } \\
\hline Collector current $\left(\mathrm{I}_{\mathrm{c}}\right)$ & Type \\
\hline Bus voltage $\left(\mathrm{V}_{\text {bus }}\right)$ & $13 \mathrm{~A}$ \\
\hline Gate voltage $\left(\mathrm{V}_{\text {gate }}\right)$ & $2000 \mathrm{~V}$ \\
\hline Gate resistance $\left(\mathrm{R}_{\mathrm{g}}\right)$ & $15 \mathrm{~V}$ \\
\hline Load inductanc $\left(\mathrm{L}_{\text {load }}\right)$ & $15 \Omega$ \\
\hline Junction temperature $\left(\mathrm{T}_{\mathrm{j}}\right)$ & $\begin{array}{c}22^{\circ} \mathrm{C}(\mathrm{Ambient} \\
\text { temperature })\end{array}$ \\
\hline Oscilloscope & $\begin{array}{c}\text { Tektronix DPO 7104 } \\
(\mathrm{BW}=500 \mathrm{MHz})\end{array}$ \\
\hline Voltage probe & $\begin{array}{c}\text { Differential probe } \\
(\mathrm{BW}=50 \mathrm{MHz})\end{array}$ \\
\hline Current sensor & $\begin{array}{c}\text { Rogowski coil PEM } \\
\text { CWT1 (BW=20MHz) }\end{array}$ \\
\hline Driver IC & $\begin{array}{c}\text { Concept (2SD 315 AI- } \\
33)\end{array}$ \\
\hline
\end{tabular}

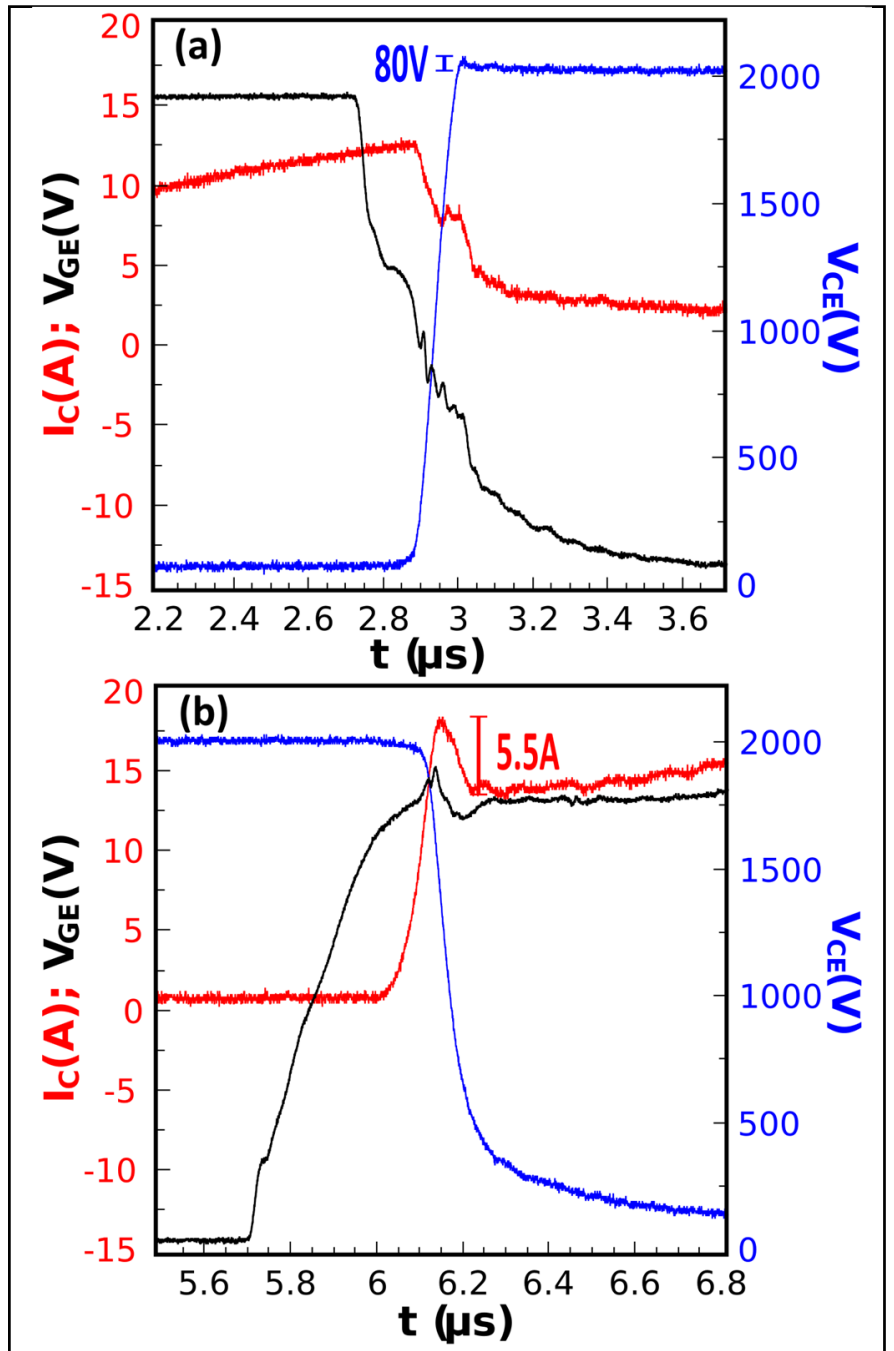

Fig. 3 Double-pulse test at room temperature showing the switching waveforms for the turn-off (a) and turn-on (b) state $\left(\mathrm{V}_{\text {gate }}=15 \mathrm{~V} ; \mathrm{R}_{\mathrm{g}}=15 \Omega\right)$.

(DUT) and the inductor is connected in parallel with the higher side switch. Fig. 3 presents the voltage and current waveforms of the lower IGBT during the switching off and on transient in the designed package.

As seen in the switching waveforms, small voltage spike accompany the turn-off transient power switches. The overshoot voltage is equal to $80 \mathrm{~V}$ over $2000 \mathrm{~V}$ bus voltage, because of the smaller parasitic inductance of this planar package compared to the conventional module. The overshoot current of 5.5A over $13 \mathrm{~A}$ is mainly due to the discharge of the output capacitance of the high side switch of the half-bridge package.

\section{CONCLUSiOn}

A planar module hybrid half-bridge based package has been presented in this paper. The complete assembly process of the hybrid package has been detailed showing the assembled planar module and its integrated turbulent cooler. A doublepulse test was carried out showing the switching waveforms with lower overshoot, comparing to that in a conventional power module. 
A thermal characterization is under investigation in order to show the benefit of the double side integrated cooler for high power applications.

\section{ACKNOWLEDGMENT}

This work is supported by the SPEED (Silicon Carbide Power Technology for Energy Efficient Devices) Project funded by the European commission FP7-Grant \#:604057.

\section{REFERENCES}

[1] J. Li, A. Castellazzi, T. Dai, M. Corfield, A. K. Solomon, and C. M. Johnson, "Built-in reliability design of highly integrated solid-state power switches with metal bump interconnects," IEEE Trans. Power Electron., vol. 30, no. 5, pp. 2587-2600, 2015.

[2] J. Li, A. Castellazzi, A. K. Solomon, and C. M. Johnson, "Reliable Integration of Double-Sided Cooled Stacked Power Switches based on $70 \mu \mathrm{m}$ Thin IGBTs and Diodes," in CIPS 2012 - 7th International Conference on Integrated Power Electronics Systems, 2012, p. 6.
[3] C. Buttay, J. Rashid, C. M. Johnson, F. Udrea, G. Amaratunga, P. Ireland, and R. K. Malhan, "Compact Inverter Designed for HighTemperature Operation," in IEEE Power Electronics Specialists Conference (PESC), 2007, pp. 2241-2247.

[4] B. Mouawad, M. Soueidan, D. Fabrègue, C. Buttay, B. Allard, V. Bley, H. Morel, and C. Martin, "Application of the Spark Plasma Sintering Technique to Low-Temperature Copper Bonding," IEEE Trans. Components, Packag. Manuf. Technol., vol. 2, no. 4, pp. 553-560, 2012.

[5] B. Mouawad, B. Thollin, C. Buttay, L. Dupont, V. Bley, D. Fabrègue, M. Soueidan, B. Schlegel, J. Pezard, and J.-C. Crebier, "Direct Copper Bonding for Power Interconnects: Design, Manufacturing and Test," IEEE Trans. components, Packag. Manuf. Technol., vol. 5, no. 1, pp. 143-150, 2015.

[6] A. Q. Huang, X. Song, and L. Zhang, "6.5 kV Si/SiC hybrid power module: An ideal next step?," in IEEE International Workshop onIntegrated Power Packaging (IWIPP), 2015, pp. 64-67.

[7] P. Beckedahl, M. Spang, and O. Tamm, "Breakthrough into the third dimension - Sintered multi layer flex for ultra low inductance power modules," in 8th International Conference on Integrated Power Electronics Systems (CIPS), 2014, pp. 461-465. 